\title{
PFDs That Work
}

$\mathbf{P}$ ersonal Flotation Devices (PFDs) prevent fisherman deaths, yet many fisherman don't wear them. To identify more wearable PDFs, researchers asked 50 West Coast Dungeness crab fishermen to rate the comfort and acceptability of a PDF after wearing it for 30 days. This document shows which PFDs were preferred by Dungeness crabbers.

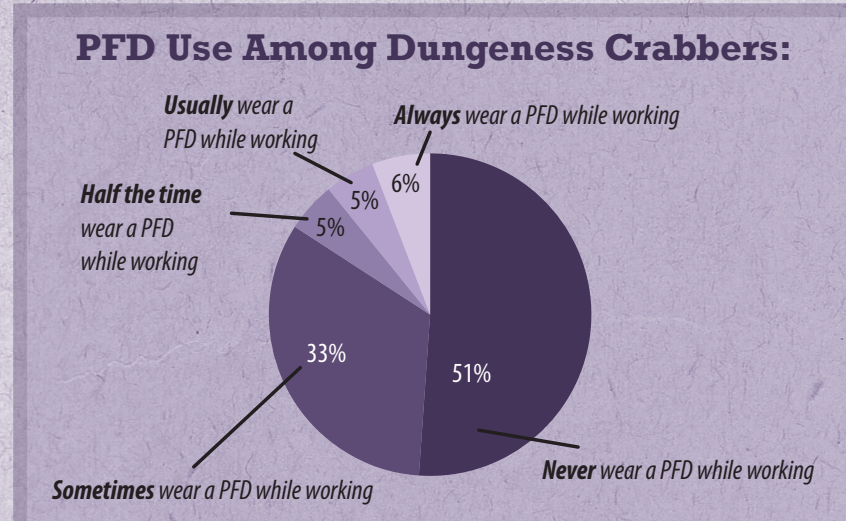

Dungeness Crabbers' Responses to Survey:

- More than half of Dungeness crab fishermen never wear a PFD while working on deck or crossing a river bar

- $20 \%$ of crabbers surveyed had fallen overboard

- Primary factors for not wearing a PFD include lack of comfort, potential for gear entanglement, and interfering with movement

More than three out of five Dungeness crab fishermen have personally known other crabbers that have been on a boat that capsized.

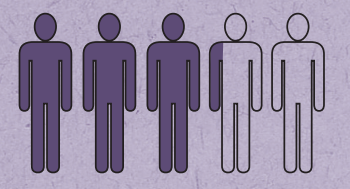

\section{PFD Evaluation:}

After 30 days of wearing and evaluating five different PFDs, Dungeness crabbers preferred the Mustang inflatable vest and the Stearns foam vest. Comments on these devices include:

- Comfortable to wear

- Lightweight and low profile

- Did not rub or chafe

"I really liked it [the IMustang Work Vest] a lot. It was easy to use and wear"

-Study Participant

"It [the Stearns foam vest] was the most comfortable PFD I have ever worn.
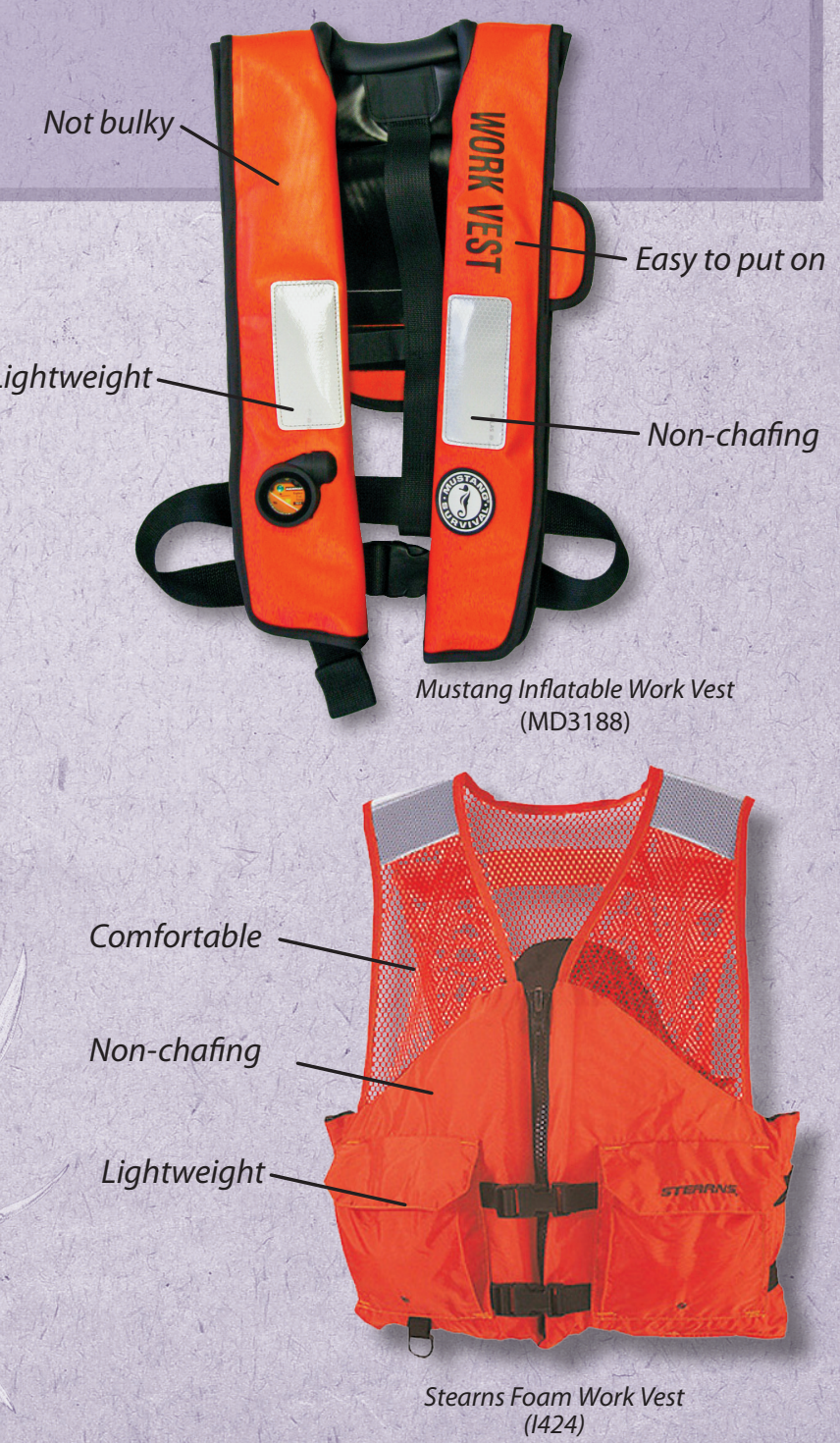


\section{Background on PFD Study in the West Coast Dungeness Fishery}

The West Coast Dungeness crab fishery is one of most dangerous fisheries in the U.S. During 2000-2013, $33 \mathrm{crab}$ fishermen drowned. None were wearing PFDs at the time of the incidents. Those deaths might have been prevented if the fishermen had been wearing PFDs.

Researchers with Oregon Health Science University, University of Washington, and the National Institute for Occupational Safety and Health conducted an evaluation with West Coast Dungeness crab fishermen to rate the comfort and acceptability of five personal flotation devices (PFDs). Marine safety experts learned that some of the most common objections to wearing a PFD are that they are bulky, heavy, uncomfortable, and put the fisherman at risk of entanglement. Fishermen have also expressed concerns that PFDs could snag on fishing gear. After a 30-day evaluation of PFDs on board Dungeness crabbing vessels, these objections were addressed through selecting the proper PFDs.'

\section{Recommendations for all Fishermen}

There are many models and styles of PFDs available today that are designed for commercial fishing and preferred by Dungeness crabbers. When choosing a PFD try on a variety of styles and models to find the one that works best for the type of work to be done.

The best PFD is the one that is worn on deck!

All vessel operators should have a PFD policy for their crew. Examples of PFD polices include:

- PFDs must be worn $100 \%$ of the time on deck

- PFDs must be worn when crossing a river bar

- PFDs must be worn when the weather turns bad

Whatever your policy is, write it down, post it, make the crew aware of it, and enforce it.

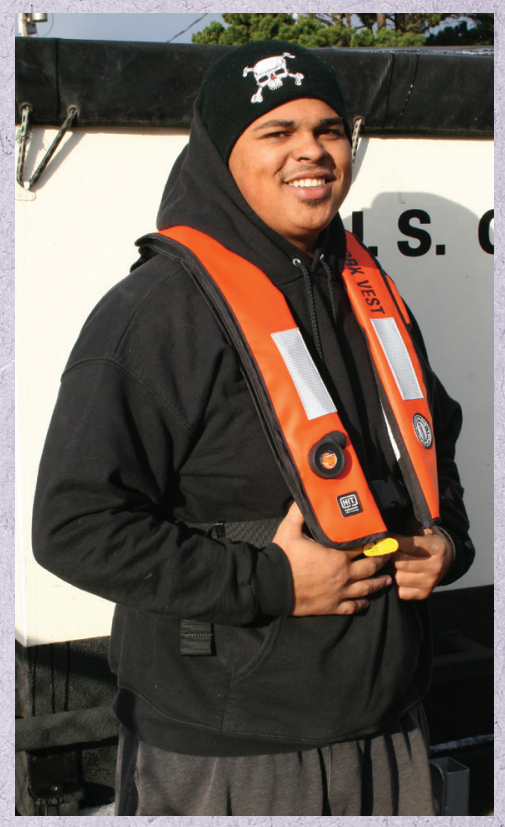

SAFER・HEALTHIER・PEOPLE

U.S. Department of Health and Human Services

Centers for Disease Control and Prevention

National Institute for Occupational Safety and Health

To receive NIOSH documents or more information about occupational safety and health topics, please contact NIOSH Telephone: 1-800-CDC-INF0 (1-800-232-4636) |TTY: 1-888-232-6348 | email: cdcinfo@cdc.gov/www.cdc.gov/niosh For a monthly update on news at NIOSH, subscribe to NIOSH eNews by visiting www.cdc.gov/niosh/eNews.

DHHS (NIOSH) Publication Number: 2015-180, May 2015

For a full report describing the study and its results, please refer to the following website: http://deohs.washington,edu/FRCG/project/ crabpfd. Project funded through the Pacific Northwest Agricultural Safety and Health Center (NHOSH/CDC Award 2 U50 0H007544).

The use of trade names and commercial sources is for identification purposes only and does not imply endorsement by the National Institute for Occupational Safety and Health (NIOSH), the Centers for Disease Control and Prevention (CDC), or the U.S. Department of Health and Human Services (HHS) or imply that one product is preferred by NIOSH, CDC, or HHS over other products manufactured by other companies. The products identified in this brochure are based on the results of the study referenced above which was designed to identify barriers and objections to PFD use and highlight the PFD features preferred by study participants.

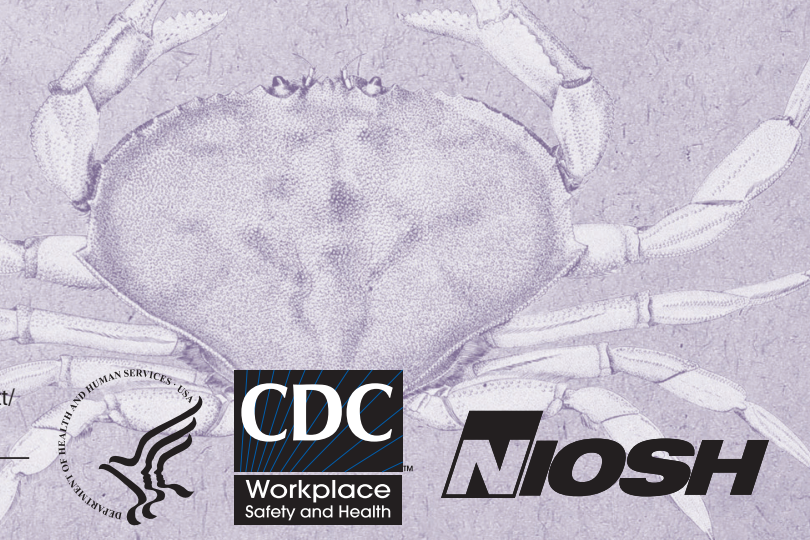

For more information on commercial fishing safety research at NIOSH visit: www.cdc.gov/niosh/topics/fishing 